\title{
PENGARUH PERSONAL SELLING DAN WORD OF MOUTH TERHADAP PENGAMBILAN KEPUTUSAN MAHASISWA MEMILIH KULIAH DI STIE EKA PRASETYA
}

\author{
Ihdina Gustina $^{1} \quad$ Viviani $^{2}$ \\ Program Studi Manajemen \\ Sekolah Tinggi Ilmu Ekonomi Eka Prasetya \\ idhina@gmail.com \\ viviani@gmail.com
}

\begin{abstract}
This study aims to determine the effect of Personal Selling and Word of Mouth on Students' Decisions to Study at STIE Eka Prasetya.

The research methodology used is quantitative descriptive method. The type of data used in this study is quantitative data, obtained in the form of numbers. Sources of data in the form of primary data and secondary data. Primary data were obtained from questionnaires, secondary data obtained from companies, journals and books relating to Personal Selling and Word of Mouth and Study Decisions. The population and sample in this study amounted to 268 customers. The results showed that Personal Selling and Word of Mouth had a positive and significant influence on learning decisions at STIE Eka Prasetya. Personal Selling and Wod of Mouth can explain the Study Decision of 49.4\% and the remaining $50.6 \%$ is influenced by other variables outside this study such as price, sales promotion and service quality.
\end{abstract}

Keywords: Personal Selling, Product Quality, Purchasing Decision

\section{PENDAHULUAN}

Perkembangan perekonomian di Indonesia saat ini telah mendorong pertumbuhan pendidikan yang sangat cepat. Perusahaan dalam menjalankan aktifitasnya memerlukan sumber daya manusia yang berkompeten dan kreatif. Pendidikan merupakan modal utama dalam menghasilkan orang-orang yang berkualitas. Setiap perusahaan atau entrepreneur muda menjadikan pendidikan adalah faktor paling menunjang dalam meraih keberhasilan masa depan. Menurut The Bureau of Labor Statistics melaporkan bahwa sektor penyedia jasa akan terus menjadi penghasil lapangan kerja dominan dalam ekonomi, menambah sekitar 20 juta pekerja pada tahun 2014 (Kotler dan Keller 2009:35). Peluang tersebut dapat bertambah dengan menciptakan sumber daya manusia yang cerdas agar kelak produk produk kreatif dan inovatif dapat dihasilkan didalam negeri, dapat menarik minat dari bangsa sendiri dan juga bangsa lain. Kemampuan sumber daya manusia agar dapat bersaing serta menciptakan peluang usaha dan dapat bersaing dengan negara luar maka tidak terlepas dari pendidikan yang baik dan bermutu, sehingga menghasilkan sumber daya manusia yang cerdas dan berkualitas.

Sektor yang paling utama dalam menciptakan sumber daya yang cerdas dan berkualitas adalah sektor pendidikan khususnya pendidikan tinggi dimana kemandirian, pusat pelatihan dan penelitian telah diterapkan sehingga menjadikan masyarakat Indonesia lebih unggul dan kompetitif. Pendidikan tinggi juga memiliki 
nilai prestisius bagi mahasiswa yang berada didalamnya.

Keputusan melanjutkan pendidikan setelah lulus dari sekolah menengah umum kejenjang yang lebih tinggi, pastinya calon mahasiswa memiliki pertimbangan dalam memilih perguruan tinggi yang sesuai dengan harapan yang diinginkan. Pada kenyataannya, pembuat pilihan (choice making) memiliki banyak pilihan. Memilih dalam hal ini merupakan suatu upaya dalam pengambilan keputusan (decision making). Pengambilan keputusan Menurut Kotler dan Keller (2009) yaitu pengenalan kebutuhan, pencarian, evaluasi alternatif, keputusan pembelian, perilaku setelah pembelian.

Dalam proses pengambilan keputusan ini calon mahasiswa melalui tahap-tahapan seperti pengenalan tempat melanjutkan kuliahnya, informasi dan penilaian terhadap keputusan yang akan diambil. Calon mahasiswa biasanya mencari dari segala sumber seperti media massa, elektronik dan internet. Pencarian informasi terkadang juga bisa didapat langsung orang atau marketing yang ada dalam perguruan tinggi tersebut.

Dalam rangka membantu calon mahasiswa untuk mendapatkan informasi STIE Eka Prasetya melakukan kegiatan yang disebut promosi. Promosi adalah cara mengkomunikasikan barang dan jasa yang di tawarkan supaya konsumen mengenal dan membeli (Suryana 2001 : 112). Adapun promosi yang dilakukan oleh STIE Eka Prasetya adalah Personal Selling dan Word Of Mouth. Personal Selling adalah penjualan tatap muka adalah sebuah pengungkapan secara lisan dalam menghadapi seorang atau beberapa calon pembeli dengan maksud untuk menciptakan penjualan (Alma 2005 : 185).

Semakin sering personal selling yang dilakukan dari suatu perguruan tinggi maka mencerminkan nilai kualitas SDM yang ada dari perguruan tinggi tersebut. Personal Selling bukan suatu hal yang mudah. Dikarenakan banyaknya pesaing yang ada diluar sana. Personal selling yang dilakukan secara baik dan benar akan meningkatkan dan mengembangkan perguruan tinggi tersebut.
Personal Selling yang telah dilakukan oleh STIE Eka Prasetya yaitu :

a. Melakukan kunjungan ke berbagai sekolah dan memberikan presentasi

b. Melakukan bazar untuk anak-anak SMA 3

c. Mengikuti education expo atau bazar pendidikan di beberapa sekolah.

Kompetisi yang cukup tajam terhadap sektor jasa pendidikan membuat para pesaing untuk memberikan pelayanan dan harga yang sangat bersaing serta promosi untuk memasarkan jasa dengan berbagai cara seperti memasang iklan, koran, televisi, radio dan media elektronik serta media cetak dimana anggaran yang dibutuhkan juga terlampau tinggi. Namun, metode pemasaran Personal Selling masih merupakan jenis aktifitas pemasaran yang efektif.

Promosi yang selanjutnya dilakukan oleh STIE Eka Prasetya adalah Word Of Mouth. Word of Mouth merupakan proses komunikasi yang berupa pemberian rekomendasi baik secara individu maupun kelompok terhadap suatu produk atau jasa yang bertujuan untuk memberikan informasi secara personal (Kotler dan Keller, 2012).

Word Of Mouth atau komunikasi dari mulut ke mulut memang mempunyai pengaruh yang sangat besar kepada seseorang karena informasi yang didapat dianggap nyata dan jujur dan seseorang cenderung lebih mempercayai informasi produk atau jasa yang mereka dengar dari teman, kerabat atau orang terdekat yang berpengalaman terhadap suatu produk tersebut dibandingkan dengan informasi dari iklan. Word of mouth atau komunikasi dari mulut ke mulut akan terjadi secara alami ketika orang menjadi pendukung suatu merek produk atau jasa karena puas dengan produk atau jasa yang dipakai atau dikonsumsinya dan memiliki hasrat atau keinginan yang muncul dari diri sendiri serta antusias untuk mengajak orang lain memilih produk atau jasa yang telah dipakainya atau bisa disebut sebagai Organic Word of Mouth.

Word Of Mouth yang dilakukan oleh STIE Eka Prasetya adalah salah satunya mahasiswa yang memberikan informasi tentang STIE Eka Prasetya kepada keluarga, 
sahabat atau siapa saja membutuhkan informasi tentang perkuliahan. Word of Mouth bisa dilakukan dengan mengajak konsumen atau calon konsumen bertemu.

Semua kegiatan promosi tersebut sama-sama dilakukan oleh perguruan tinggi swasta yang lain, namun hasil setiap tahunnya terdapat perbedaan jumlah mahasiswa yang masuk ke STIE Eka Prasetya dengan perguruan tinggi yang lain. Di STIE Eka Prasetya sendiri terdapat peningkatan jumlah mahasiwa dalam penerimaan mahasiswa baru setiap tahunnya. Data jumlah mahasiswa dari tahun 2015-2018 dapat dilihat pada table 1.1 berikut ini.

Tabel 1. Total Mahasiswa Tahun 2015-2018

\begin{tabular}{|c|c|c|}
\hline No & Tahun & Jumlah \\
\hline 1. & 2015 & 145 \\
\hline 2. & 2016 & 159 \\
\hline 3. & 2017 & 180 \\
\hline 4. & 2018 & 327 \\
\hline
\end{tabular}

Mahasiswa yang kuliah di STIE Eka Prasetya berasal dari kota Medan dan dari luar kota Medan, dapat dilihat pada tabel 2 berikut.

Tabel 2.Data Mahasiswa Dari Medan dan Luar Kota Medan Tahun 2015-2018

\begin{tabular}{|c|c|c|c|}
\hline No. & Tahun Ajaran & Medan & Luar Medan \\
\hline 1 & 2015 & 126 & 19 \\
\hline 2 & 2016 & 137 & 22 \\
\hline 3 & 2017 & 154 & 26 \\
\hline 4 & 2018 & 264 & 63 \\
\hline
\end{tabular}

Sumber : STIE Eka Prasetya, 2019

TINJAUAN PUSTAKA DAN HIPOTESIS Keputusan Pembelian

Menurut Kotler dan Keller (2012:123)

Keputusan Pembelian adalah beberapa tahapan yang dilakukan oleh konsumen sebelum melakukan keputusan pembelian suatu produk.

Menurut Kotler dan Keller (2012:161), indikator keputusan pembelian terdiri dari :

1. Pemilihan produk

2. Pemilihan merek

3. Pemilihan penyalur

4. Jumlah pembelian

5. Penentuan waktu kunjungan
6. Metode pembayaran

7. Perilaku pasca pembelian

\section{Personal Selling}

Menurut Hermawan (2012:106) Personal Selling merupakan pemasaran produk atau jasa dimana penjual bertemu langsung dengan pembeli untuk menjajaki prospek (peluang) pembelian.

Menurut Hermawan (2012:118-120) indikator Personal Selling yaitu :

1. Mencari prospek

2. Prestasi dan demostrasi

3. Tindak lanjut

4. Menutup penjualan

Word Of Mouth

Menurut Sernovitz (2009), Word Of

Mouth adalah pembicaraan yang secara alami terjadi antara orang-orang.

Menurut Sernovitz

(2009:31)

menyebutkan bahwa ada 5 indikator/elemen yang dibutuhkan untuk Word of Mouth agar dapat menyebar :
1. Talkers
2. Topics
3. Tools
4. Talking part
5. Tracking

Pengujian hipotesis penelitian :

$\mathrm{H} 1=$ Personal Selling berpengaruh signifikan terhadap keputusan memilih kuliah di STIE Eka Prasetya Medan.

$\mathrm{H} 2=$ Word Of Mouth berpengaruh signifikan terhadap keputusan memilih kuliah di STIE Eka Prasetya Medan.

H3 = Personal Selling dan Word Of Mouth berpengaruh signifikan terhadap keputusan memilih kuliah di STIE Eka Prasetya Medan. 
Berdasarkan uraian yang telah dijelaskan, maka dapat digambarkan kerangka pemikirannya sebagai berikut :

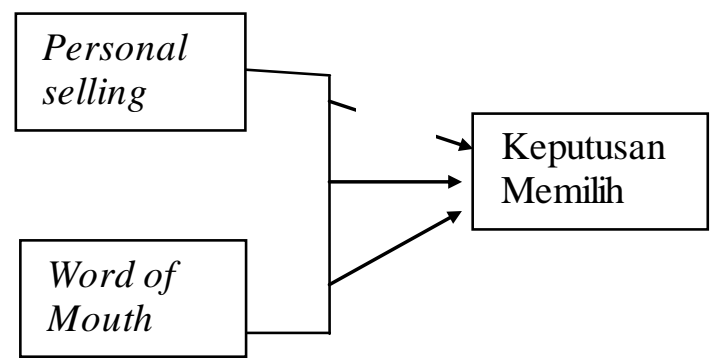

Gambar 1. Kerangka Pemikiran

\section{METODOLOGI PENELITIAN}

Lokasi Penelitian

Tempat pelaksanaan aktifitas penelitian ini dilaksanakan di STIE Eka Prasetya yang beralamat di Jl. Merapi No. 8 Medan.

\section{Populasi dan Sampel}

Dalam penelitian ini yang menjadi populasi adalah Mahasiswa STIE Eka Prasetya sebanyak 268 mahasiswa. Teknik pengambilan sampel dalam penelitian ini menggunakan sampel jenuh.

\section{Uji Validitas dan Reliabilitas \\ Uji Validitas}

Hasil uji Validitas dapat dilihat pada tabel 1.

Tabel 3. Hasil Uji Validitas

\begin{tabular}{llrr}
\hline No & Pernyataan & Variabel & rhitung \\
\hline 1. & PS-1 & & 0,851 \\
2. & PS-2 & & 0,813 \\
3. & PS-3 & Personal & 0,886 \\
4. & PS-4 & Selling & 0,777
\end{tabular}

\begin{tabular}{llcc}
\hline 1. & WOM-1 & & 0,870 \\
2. & WOM -2 & & 0,797 \\
3. & WOM -3 & Word Of & 0,423 \\
4. & WOM -4 & Mouth & 0,769 \\
5. & WOM -5 & & 0,773 \\
\hline 1. & KM-1 & & 0,743 \\
2. & KM-2 & & 0,795 \\
3. & KM-3 & & 0,717 \\
4. & KM-4 & Keputusan & 0,687 \\
5. & KM-5 & Memilih & 0,780 \\
6. & KM-6 & & 0,766 \\
7. & KM-7 & & 0,669
\end{tabular}

Sumber : Hasil Olah Data, 2019

Tabel 3 menunjukkan bahwa semua pernyataan untuk variabel Keputusan Memilih (Y) dinyatakan valid.

\section{Uji Reliabilitas}

Hasil uji Reliabilitas dapat dilihat pada tabel 4.

\begin{tabular}{llcl}
\multicolumn{4}{c}{ Tabel 4. Hasil Uji Reliabilitas } \\
\hline No. & Variabel & $\begin{array}{l}\text { Jumlah } \\
\text { Item }\end{array}$ & $\begin{array}{l}\text { Cronbach's } \\
\text { Alpha }\end{array}$ \\
\hline 1. & $\begin{array}{l}\text { Personal } \\
\text { Selling }\end{array}$ & 4 & 0,852 \\
2. & $\begin{array}{l}\text { Word } \text { Of } \\
\text { Mouth }\end{array}$ & 5 & 0,878 \\
3. & $\begin{array}{l}\text { Keputusan } \\
\text { Memilih }\end{array}$ & 7 & 0,860 \\
\hline
\end{tabular}

Sumber : Hasil Olah Data, 2019

Dari Tabel 4 di atas menunjukkan bahwa reliabilitas semua variabel dapat dikategorikan baik.

\section{Uji Asumsi Klasik}

Uji Normalitas

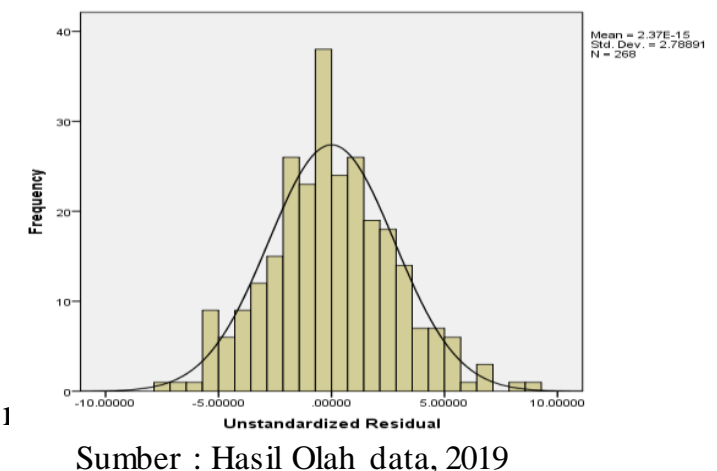

Gambar 2. Grafik Histogram

Gambar 2 memperlihatkan bahwa data telah berdistribusi normal. Hal ini dapat dilihat dari grafik histogram yang menunjukkan bahwa grafik histogram tidak melenceng ke kiri maupun melenceng ke kanan. 


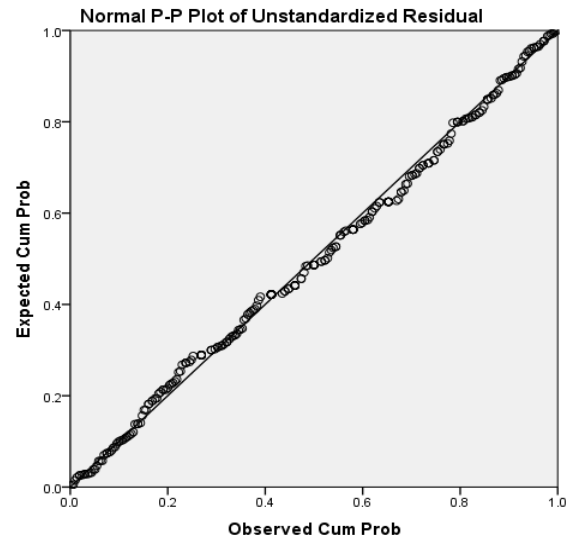

Gambar 3. Grafik Normality P Plot

Dari Gambar 3 dapat dilihat bahwa data menyebar disekitar garis diagonal sehingga dapat disimpulkan data berdistribusi normal.

\section{Uji Normalitas One Kolmogrov Sminrov}

Tabel 5. Uji Kolmogrov Smirnov

One-Sample Kolmogorov-Smirnov Test

\begin{tabular}{|ll|l|}
\hline & & $\begin{array}{l}\text { Unstandardi } \\
\text { zed } \\
\text { Residual }\end{array}$ \\
\hline $\mathrm{N}$ & & 268 \\
Normal Parameters $^{\mathrm{a}, \mathrm{b}}$ & Mean & .0000000 \\
& & Std. \\
& Deviation & 2.78891070 \\
Most Extreme & Absolute & .045 \\
Differences & Positive & .045 \\
& Negative & -.041 \\
Test Statistic & & .045 \\
Asymp. Sig. (2-tailed) & & $.200^{\mathrm{c,d}}$ \\
\hline
\end{tabular}

a. Test distribution is Normal.

b. Calculated from data.

c. Lilliefors Significance Correction.

d. This is a lower bound of the true significance.

Sumber : Hasil Olah Peneliti, 2019

Berdasarkan Tabel 5 menunjukkan bahwa nilai signifikannya (Asymp.Sig) adalah 0,894 yang lebih besar dari 0.05. Dengan demikian dapat disimpulkan bahwa data telah berdistribusi normal.

\section{Uji Multikoline aritas}

Menurut Ghozali (2016:103), uji multikolonieritas bertujuan untuk menguji apakah model regresi ditemukan adanya korelasi antar variabel bebas (independen). Model regresi yang baik seharusnya tidak terjadi korelasi di antara variabel independen. Variabel Personal Selling $\left(\mathrm{X}_{1}\right)$ dan Word Of Mouth $\left(\mathrm{X}_{2}\right)$ mempunyai nilai tolerance sebesar 0,673 yang lebih besar dari 0,1 sehingga memenuhi syarat. Nilai VIF dari variabel Personal Selling $\left(\mathrm{X}_{1}\right)$ dan Word Of Mouth $\left(\mathrm{X}_{2}\right)$ juga memenuhi syarat yaitu 1,485 yang lebih kecil dari 10 sehingga dapat disimpulkan bahwa pada kedua variabel tidak terjadi gejala multikolinearitas.

\section{Uji Heteroskedastisitas}

Berdasarkan hasil olah data uji heteroskedastisitas dapat dilihat pada gambar 4 berikut.

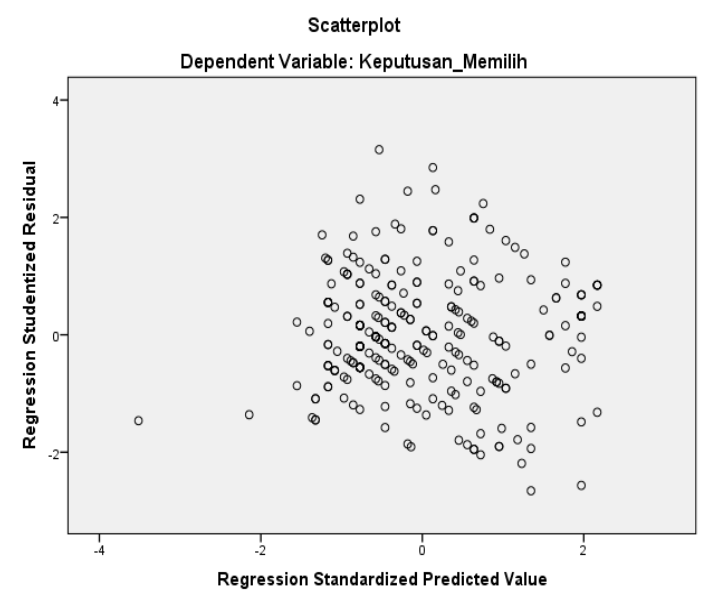

Sumber : Hasil Penelitian, 2019 (Data diolah) Gambar 4 Uji Heteroskedastisitas

Berdasarkan Gambar 4 dapat dilihat bahwa data menyebar dengan pola yang tidak jelas baik di atas maupun dibawah angka nol (0) pada sumbu Y, tidak berkumpul di satu tempat, dapat disimpulkan bahwa tidak terjadi heteroskedastisitas.

\section{Hasil Analisis Regresi Linear Berganda}

Hasil olah data untuk regresi linier berganda dapat dilihat pada tabel 6 berikut. 
Tabel 6. Analisis Regresi Linear Berganda

Pada Tabel 6, diperoleh persamaan

\begin{tabular}{|c|c|c|c|c|c|}
\hline \multirow{2}{*}{ Model } & \multicolumn{2}{|c|}{$\begin{array}{l}\text { Unstandardized } \\
\text { Coefficients }\end{array}$} & \multirow{2}{*}{$\begin{array}{c}\begin{array}{c}\text { Standar } \\
\text { dized } \\
\text { Coeffic } \\
\text { ients }\end{array} \\
\text { Beta }\end{array}$} & \multirow{2}{*}{$\mathrm{t}$} & \multirow{2}{*}{ Sig. } \\
\hline & B & $\begin{array}{c}\text { Std. } \\
\text { Error }\end{array}$ & & & \\
\hline $\begin{array}{l}\text { (Constant } \\
\text { ) }\end{array}$ & $\begin{array}{c}11 . \\
03 \\
4\end{array}$ & .994 & & $\begin{array}{c}11.10 \\
3\end{array}$ & $\begin{array}{c}.00 \\
0\end{array}$ \\
\hline $\begin{array}{l}\text { Personal } \\
\text { _Selling }\end{array}$ & $\begin{array}{l}.54 \\
4 \\
\end{array}$ & .074 & .389 & 7.303 & $\begin{array}{c}.00 \\
0\end{array}$ \\
\hline $\begin{array}{l}\text { Word } \\
\text { _Of } \\
\text { _Mouth }\end{array}$ & $\begin{array}{c}.43 \\
0\end{array}$ & .057 & .404 & 7.592 & $\begin{array}{c}.00 \\
0\end{array}$ \\
\hline & & & & & \\
\hline
\end{tabular}

regresi linear berganda seperti berikut :

Keputusan Memilih $=11,034+0,544$ Personal Selling + 0,430Word Of Mouth + e

Makna dari penjelasan analisis regresi linear berganda diatas adalah :

1. Konstanta sebesar 11,034

Apabila Personal selling dan Word Of Mouth tidak mengalami peningkatan atau konstan maka Keputusan Memilih sebesar 11,034 satuan.

2. Setiap terjadi peningkatan sebesar satu satuan untuk variabel Personal selling maka Keputusan Memilih sebesar 0,544 satuan dengan anggapan variabel lainnya tetap.

3. Setiap terjadi peningkatan sebesar satu satuan untuk variabel Word Of Mouth maka Keputusan Memilih sebesar 0,430 satuan dengan anggapan variabel lainnya tetap.

\section{Uji Hipotesis}

Uji t (Uji Parsial)

Dari hasil olah data (SPSS) untuk uji $\mathrm{t}$ (uji parsial) diperoleh :

1. Nilai $t_{\text {hitung }}$ untuk variabel Personal Selling adalah 7,303 dengan signifikan 0,00. Dengan derajat bebas (df) sebesar 266 dan taraf sig $\alpha=5 \%$ maka nilai $\mathrm{t}_{\text {tabel }}$ adalah sebesar 1,968 . Oleh karena nilai $t_{\text {hitung }}>t_{\text {tabel }}$ maka $\mathrm{H}_{\mathrm{o}}$ ditolak, $\mathrm{H}_{\mathrm{a}}$ diterima sehingga Personal Selling secara parsial berpengaruh dan signifikan terhadap Keputusan mahasiswa Memilih kuliah di STIE Eka Prasetya.

2. Nilai thitung untuk variabel Word Of Mouth adalah 7,592 dengan signifikan 0,000. Dengan derajat bebas (df) sebesar 266 dan taraf sig $\alpha=5 \%$ maka nilai $\mathrm{t}_{\text {tabel }}$ adalah sebesar 1,968 . Oleh karena nilai $t_{\text {hitung }}>t_{\text {tabel }}$ maka $\mathrm{H}_{\mathrm{o}}$ ditolak, $\mathrm{H}_{\mathrm{a}}$ diterima sehingga Word Of Mouth secara parsial berpengaruh dan signifikan terhadap Keputusan mahasiswa Memilih kuliah di STIE Eka Prasetya

\section{Uji F (Uji Serempak)}

Berdasarkan hasil olah data (SPSS) untuk uji F (uji serempak) adalah :

nilai $F_{\text {hitung }}$ sebesar 129,474 dengan tingkat signifikan 0,000 . Untuk tingkat keyakinan $95 \% \mathrm{df}_{1}=2$ dan $\mathrm{df}_{2}=265$ maka $\mathrm{F}_{\text {tabel }}$ adalah 3,03. Oleh karena $F_{\text {hitung }}>F_{\text {tabel }}$ maka kriterianya adalah $\mathrm{H}_{\mathrm{a}}$ diterima sehingga dapat dinyatakan bahwa Personal Selling dan Word Of Mouth secara serempak berpengaruh dan berdampak terhadap Keputusan mahasiswa memilih kuliah di STIE Eka Prasetya.

\section{Uji Koefisien Determinasi $\left(\mathbf{R}^{2}\right)$}

Dari hasil olah data (SPSS) untuk uji

Koefisien Determinasi diperoleh :

Dari table diatas bahwa $R$ Square adalah sebesar 0.494 berarti Personal Selling dan Word Of Mouth dapat menjelaskan Keputusan Pembelian sebesar 49,4\% dan sisanya 50,6\% $(100-49,4)$ dipengaruhi oleh variabel lain di luar dari penelitian ini seperti merek, promosi penjualan, kualitas pelayanan dan sebagainya.

\section{PEMBAHASAN}

Hasil perhitungan diketahui bahwa koefisien determinasi $R$ Square yang digunakan untuk mengukur seberapa jauh kemampuan model dalam menerangkan variasi variabel dependen adalah 0,494. Hal ini menunjukkan bahwa 49,4\% Keputusan mahasiswa memilih kuliah di STIE Eka Prasetya dipengaruhi oleh variabel, Personal Selling dan Word Of Mouth sedangkan $50,6 \%$ dipengaruhi oleh variabel- 
variabel lainnya yang tidak diteliti dalam penelitian ini.

$$
\text { Hasil perhitungan } F_{\text {hitung }} \text { sebesar }
$$

129,474 dengan tingkat signifikan 0,000. Untuk tingkat keyakinan $95 \% \mathrm{df}_{1}=2$ dan $\mathrm{df}_{2}=$ 265 maka $\mathrm{F}_{\text {tabel }}$ adalah 3,03. Oleh karena $F_{\text {hitung }}>F_{\text {tabel }}$ maka kriterianya adalah $\mathrm{H}_{\mathrm{o}}$ ditolak sehingga dapat dinyatakan bahwa Personal Selling dan Word Of Mouth secara serempak berpengaruh dan berdampak terhadap Keputusan mahasiswa memilih kuliah di STIE Eka Prasetya.

Hasil perhitungan nilai $t_{\text {hitung }}$ untuk variabel Personal Selling adalah 7,303 dengan signifikan 0,000. Dengan derajat bebas (df) sebesar 266 dan taraf sig $\alpha=5 \%$ maka nilai $t_{\text {tabel }}$ adalah sebesar 1,968 . Oleh karena nilai $t_{\text {hitung }}>$ $\mathrm{t}_{\text {tabel }}$ maka kreiterianya adalah $\mathrm{H}_{\mathrm{a}}$ diterima sehingga Personal Selling secara parsial berpengaruh dan signifikan terhadap Keputusan mahasiswa Memilih kuliah di STIE Eka Prasetya. Hasil ini sesuai dengan penelitian sebelumnya Mohammad Rizan (2013) yang menemukan Personal Selling berpengaruh yang signifikan terhadap kepuasan pelanggan Majalah Info Bekasi.

Hasil perhitungan Nilai $t_{\text {hitung }}$ untuk variabel Word Of Mouth adalah 7,592 dengan signifikan 0,000. Dengan derajat bebas (df) sebesar 266 dan taraf sig $\alpha=5 \%$ maka nilai $t_{\text {tabel }}$ adalah sebesar 1,968. Oleh karena nilai $t_{\text {hitung }}>t_{\text {tabel }}$ maka kreiterianya adalah $\mathrm{H}_{\mathrm{a}}$ diterima sehingga Word Of Mouth secara parsial berpengaruh dan signifikan terhadap Keputusan mahasiswa Memilih kuliah di STIE Eka Prasetya. Hasil penelitian ini sesuai dengan penelitian sebelumnya Prabowo Indra (2016) yang menemukan Word of Mouth berpengaruh signifikan terhadap keputusan pengguna Iphone.

\section{KESIMPULAN}

Berdasarkan dari hasil penelitian dan pembahasan, maka dapat disimpulkan bahwa :

1. Peningkatan pelayanan melalui Personal Selling akan meningkatkan keputusan mahasiswa untuk memilih kuliah di STIE Eka Prasetya
2. Melayani calon mahasiswa melalui Word of Mouth yang baik mempengaruhi mahasiswa untuk memilih kuliah di STIE Eka Prasetya.

3. Personal Selling dan Word of Mouth merupakan kedua variabel yang mempengaruhi positif dan signifikan mahasiswa kuliah di STIE Eka Prasetya

\section{Saran}

Dari hasil penelitian Personal Selling dan Word of Mouth baik secara parsial, maupun simultan mempengaruhi keputusan mahasiswa memilih kuliah di STIE Eka Prasetya, hal ini menjadi masukan kepada pihak manajemen untuk meningkatkan kedua variabel tersebut dalam memberikan pelayanan kepada mahasiswa, seperti memperbaiki Personal, memperbanyak media informasi tentang perkuliahan. Dan pihak manajemen juga dapat mempertimbangkan variabel lainnya yang mempengaruhi secara signifikan terhadap keputusan mahasiswa untuk memilih kuliah di STIE Eka Prasetya, seperti variabel citra merk, dan pengaruh teknologi.

\section{DAFTAR PUSTAKA}

Arikunto, Suharsimi. 2010. Prosedur Penelitian. Jakarta: PT. Rineka Cipta.

Assauri, Sofjan. 2011. Manajemen Pemasaran. Jakarta: PT. Raja Grafindo Persada

Arya Nugraha W,Ni Wayan Sri S,Ni Nyoman Kerti Yasa 2016. Pengaruh Kualitas Pelayanan dan Citra terhadap kepuasan dan Word of mouth Nasabah PT.Bank Pembangunan,Bali

Assauri, Sofjan. 2011. Manajemen Pemasaran. Jakarta: PT. Raja Grafindo Persada

Ghozali, Imam. 2011. Pengenalan SPSS. Jakarta : Penerbit Universitas Diponegoro. 
Hermawan, Agus. 2012. Komunikasi Pemasaran. Jakarta : Penerbit Erlangga.

Kotler, Philip. 2009. Manajamen Pemasaran, Jilid 1 dan 2. Jakarta: PT. Indeks Kelompok Gramedia

Mohammad Rizan 2013. Pengaruh Kualitas Produk dan Personal Selling Terhadap Kepuasan Pelanggna pada Majalah Info Bekasi.

Muhammad Noer Ichbal Hilman 2013. Pengaruh Word of mouth, Marketing mix (produk, harga, promosi, saluran distribusi ), dan Citra Merek terhadap Keputusan Pembelian Mobil Suzuki Swift.

Philip Kotler. 2002. Manajemen Pemasaran. Edisi Millenium, Jilid 2, PT Prenhallindo, Jakarta

Prabowo, Indra 2016. Pengaruh Citra Merek, Kualitas produk, Persepsi Harga, Word of Mouth terhadap minat beli (Studi pada Mahasiswa Fakultas Ekonomi UNY pengguna iPhone).

Sernovitz. 2009. Word of Mouth Marketing . Jakarta. Gramedia Pustaka Utama.

Sugiyono. 2012. Metode Penelitian Bisnis. Cetakan Keenambelas. Bandung : Penerbit Alfabeta

Jurnal.

Widyaswati,Rahmatya 2010. Analisis faktorfaktor yang mempengaruhi kepuasan sehingga tercipta Word of mouth yang positif pada pelanggan Speedy di Semarang. 